\title{
Fetal Outcome in Hypertensive Disorders of Pregnancy.
}

Arju Chand Singh ${ }^{l}$, Sadikchya Singh Rana ${ }^{l}$.

\section{Department of Obstetrics and Gynaecology, Shree Birendra Hospital.}

\section{ABSTRACT}

Introduction: Hypertensive disorders are the most common medical complications of pregnancy, affecting approximately $5-10 \%$ of pregnancies and the major cause of maternal and infant disease and death worldwide. Very few researches have been done in Nepal to analyze the effect of hypertension in fetus. The aim of this study was to determine the incidence and perinatal morbidity of hypertensive disorders of pregnancy.

Methods: This was a hospital based prospective observational study conducted at Paropakar Maternity and Women's hospital. The study was conducted from 18th October to 22nd December 2007. All primi and multigravid patient with $\mathrm{BP} \geq 140 / 90 \mathrm{mmHg}$ after 28 weeks of pregnancy were included in the study. Women with a blood pressure $\geq 140 / 90 \mathrm{mmHg}$ at or before 20 weeks of gestation, previous hypertension or women on antihypertensive drugs and Intrauterine fetal death (IUFD) were excluded from the study.

Results: A total of 126 cases of hypertensive disorders of pregnancy were identified among 3819 obstetric cases. The incidence of hypertensive disorders of pregnancy was 3.3\%. Among 100 cases who were included in the study, 42 had pre eclampsia and 58 had gestational hypertension. Among 42 preeclamptic patients, 15(35.71\%) had low birth weight babies, and 9(15.5\%) babies had low birth weight among 58 gestational hypertensive mothers.

Conclusions: Preeclampsia increases the risk of intrauterine growth restriction, low birth weight and stillbirth.

Keywords: hypertension; low birth weight; preeclampsia.

\section{INTRODUCTION}

Hypertensive disorders are the most common medical complications of pregnancy, affecting approximately $5-10 \%$ of pregnancies ${ }^{1}$. The incidence varies among different countries, region and hospital. The terminology used to classify hypertensive disorders of pregnancy has been inconsistent and confusing. Therefore, the classification of hypertensive disorders complicating pregnancy developed by working group of National High Blood Pressure Education Program (NHBPEP) 2000 have divided into five different types. Chronic hypertension, preeclampsia, eclampsia, gestational hypertension and preeclampsia superimposed upon chronic hypertension. Hypertensive disorders of pregnancy results in $12 \%$ of maternal deaths $^{2}$. The etiopathogenesis of hypertensive disorder of pregnancy is vasospasm and endothelial dysfunction as a consequence of utero-placental blood flow. This results in decreased placental perfusion leading to decreased supply of oxygen and nutrients necessary for fetal growth and well-being. As a result incidence of intrauterine growth restriction, low birth weight are increased and so does the perinatal mortality and morbidity. Maternal risks include hypoperfusion of major organs causing brain edema, hemorrhage and seizures.

Many western literatures have studied the perinatal effects of hypertensive disorders in pregnancy, but very little in our country. This study was conducted to see the perinatal outcome in hypertensive disorder of pregnancy in terms of low birth weight, intrauterine growth restriction and stillbirth.

\section{METHODS}

This was a hospital based prospective observational study conducted between $18^{\text {th }}$ October to $22^{\text {nd }}$ December 2007. All primi and multigravid patients with $\mathrm{BP} \geq 140 / 90 \mathrm{~mm} \mathrm{Hg}$ after 28 weeks of pregnancy were included. Women with a Blood Pressure $\geq 140 / 90$ $\mathrm{mm} \mathrm{Hg}$, at or before 28 weeks of gestation, previous history of hypertension or patients using antihypertensive drugs, hypertension in multiple gestation and intrauterine fetal death (IUFD) were excluded from the study.
Correspondence:

Arju Chand Singh

Department of Obstetrics and Gynaecology

Shree Birendra Hospital, Kathmandu, Nepal.

Email: arju.ravi@gmail.com 
After taking the approval from the institution, questionnaire was developed with the area covering the related subject of study. Written consent was taken from the patient after explaining all the aspects of the study. Confidentiality of the subject was maintained. The pretested questionnaire was filled with information details given in the record and information from the lady herself. General and systemic examination of women were carried out thoroughly and findings were recorded. Diagnosed cases of hypertensive disorders of pregnancy were noted from admission and were followed up in wards and their blood pressure was rechecked after 4-6 hours; if the DBP (Diastolic Blood Pressure) $\geq 90 \mathrm{~mm} \mathrm{Hg}$, then they were enrolled for study. Those with DBP $\geq 110 \mathrm{~mm} \mathrm{Hg}$ were also enrolled for study and classified as severe hypertension. Blood pressure was measured by sphygmomanometer cuff on the both arms in sitting position. Koratokoff 5 (K5) sound was used for diastolic blood pressure. All women who developed hypertension during intrapartum and postpartum period (within 24 hours of delivery) were also enrolled in study. Urine for protein was tested once they were diagnosed as a case of hypertensive disorders of pregnancy by sulphosalicylic acid method 12 hours apart and proteinuria was considered significant if it was $1+$ in two or more occasion. Special attention was given to Still Birth (SB), Low Birth Weight LBW $(<2.5$ $\mathrm{kg}$ ) and Intra uterine growth retardation (IUGR) as the perinatal outcome. Statistical analysis was done using SPSS v 13 software.

\section{RESULTS}

Among 3819 pregnant women seen during the study period, $126(3.3 \%)$ met the diagnostic criteria of hypertensive disorders of pregnancy. Out of these 126 cases, 26 cases were excluded from the study as they did not meet inclusion criteria. Total of 100 cases that fulfilled the inclusion criteria were analysed. Incidence of preterm birth in our study was $13 \%$. The birth

Table 1. Birth weight in relation to hypertension

\begin{tabular}{|lccc|}
\hline Birth weight in kg & Gestational HTN & Pre eclampsia & Total \\
\hline$<2.5 \mathrm{~kg}$ & $9(15.5 \%)$ & $15(35.71 \%)$ & 24 \\
$2.5-3 \mathrm{~kg}$ & $28(48.27 \%)$ & $15(35.71 \%)$ & 43 \\
$3.1-3.5 \mathrm{~kg}$ & $15(25.86 \%)$ & $10(23.81 \%)$ & 25 \\
$>3.5 \mathrm{~kg}$ & $6(10.34 \%)$ & $2(4.76 \%)$ & 8 \\
Total & 58 & 42 & 100 \\
\hline
\end{tabular}

Me dical Journal of $\mathrm{S}$ h ree B irend ra Hos pita 1
Even, Xiong $X$ and associate in Canada have found that women with preeclampsia were at markedly higher risk of having low birth weight (adjusted odds ratio, $4.14 ; 95 \%$ confidence interval, 3.32-5.15) and small for gestational age (adjusted odds ratio 2.56; $95 \%$ confidence interval, 1.92-3.41) babies ${ }^{5}$. These facts indicate that preeclampsia increases the risk of given in Table 1 . There were $15(35.7 \%)$ babies with
low birth weight $(<2.5 \mathrm{Kg})$ in pre eclamptic mother and $9(15.5 \%)$ babies had low birth weight from mothers diagnosed as gestational hypertension. $2(4.76 \%)$ cases of IUGR were diagnosed at 36 weeks of pregnancy in mother with severe pre eclampsia. The weight of new born baby who were diagnosed as IUGR was $1600 \mathrm{gm}$ and $1800 \mathrm{gm}$ respectively. There were total four still births in this study. All of them were fresh still birth, $3(17.6 \%)$ with severe hypertension and $1(1.20 \%)$ with mild hypertension at gestation of $30,31,36$ and 39 weeks.

\section{DISCUSSION}

Various studies have shown low birth weight for tational age in relation to severity of hypertension. gestational hypertension. This indicates that higher the severity of hypertension larger the chance of low of low birth weight as $24.6 \%$ among the pre eclamptic pregnancies which was higher than our study (15.7\%). finding is comparable with a retrospective cohort found the adjusted odds ratios of low birth weight were 2.65 (1.73-4.39) for preeclampsia and 2.53 (1.19for severe preeclampsia, even though the risk for gestational hypertension (adjusted odds ratio 1.56 [1.00-2.41]) as compared with pre eclampsia ${ }^{4}$. 
intrauterine growth restriction and low birth weight.

Incidence of preterm birth in our study was 13\%. Preterm delivery was higher in patients with severe pre eclampsia $(11 \%)$ in comparision to $(2 \%)$ in gestational hypertension. Studies have reported the incidence of preterm delivery ranging from $13-54 \%{ }^{6}$. Buchbinder A et al in their study done in United States of America had compared mild pre eclampsia with severe gestational hypertension. They found higher rates of preterm delivery at $<37$ weeks $(54.2 \%$ vs. $17.8 \%$, $\mathrm{p}=.001)$ and at $<35$ weeks of gestation $(25.0 \%$ vs. $8.4 \%, \mathrm{p}=.0161)$ in mothers with severe eclampsia. Similarly a prospective study done in Lithuania by Arlauskiene found a higher incidence of intrauterine growth restriction with severe pre eclampsia (38.2 $\%)$ and preterm delivery in mother with severe pre eclampsia was $69.6 \%^{8}$. All hypertensive groups had increased risks for low birth weight and preterm birth but uncomplicated pre-existing hypertension was not associated with small for gestational age infants.

The incidence of hypertensive disorders of pregnancy in this study was 3.3\% which is almost similar with the study done by Vatten and Skjaerven $(2.6 \%)^{9}$.

In this study, two cases of intrauterine growth restriction were identified. Varma TR noted 38\% intrauterine growth restriction in severe preeclampsia and 18\% intrauterine growth restriction in women with mild preeclampsia $^{10}$. Whereas, Voto at el noted $16 \%$ low birth weight in women with severe preeclampsia and $12 \%$ with mild preeclampsia ${ }^{11}$. Since our sample size is very small, we cannot make any conclusion on it. A larger study is recommended.

\section{CONCLUSIONS}

The incidence of hypertensive disorders of pregnancy was found to be $3.3 \%$. Perinatal morbidity and mortality increased in women with severe hypertension and pre eclampsia.

\section{REFERENCES}

1. Steven GG, Jennifer RN, Joe LS. Obstetrics. Hypertension normal and problem pregnancies. 1996; 4:945-7.

2. Livingston JC, Maxwell BD, Sibai BM. Chronic hypertension during pregnancy. Minerva Ginecol. 2003;55:1-13

3. Tze KL, Man WP, Daljit SS, Tse NL. Impact of hypertensive disorders of pregnancy at term on infant birth weight. Acta Obstetricia Gynecologica Scandinavica. 2005;84(9):875-7.

4. Xiong X, Mayes D. Impact of pregnancy induced hypertension on fetal growth. Am J Obstet Gynecol. 1999;180(1):207-13

5. Xiong X, Demianczuk NN, Buekens P, Saunders LD. Association of preeclampsia with high birth weight for age. Am J Obstet Gynecol. 2002;186(5):1105-6.

6. Sibai BM. Treatment of hypertension in pregnant women. $N$ Engl J Med. 1996;335(4):257-65.

7. Buchbinder A, Sibai BM, Caritis S, Macpherson C, Hauth $J$. Adverse perinatal outcomes are significantly higher in Severe gestational hypertension than in mild pre eclampsia. Am J Obstet Gynecol.2002;186(1):66-71.

8. Arlauskiene A, Drasutiene D, Drazdiene N. Assessment of fetal well being in pre eclampsia and perinatal outcomes. Acta medica Lithuanica. 1995;3:34-8.

9. Vatten LJ, Skjaervan R. Is preeclampsia more than one disease? Br J Obstet Gynecol. 2004;111(4):298-302.

10. Varma TR. Serum uric acid level as an index of fetal prognosis in pregnancies complicated by pre-existing hypertension \& pre eclampsia of pregnancy. International Journal of Gynecology \& Obstetrics. 1982;20(5):401-8.

11. Voto LS, Darbon Grosso HA, and Illia R, Margulies M. Uric acid levels: a useful index of the severity of pre eclampsia \& perinatal prognosis. Journal of perinatal medicine 1988;16(2):123-6. 